Research

Alpine rivers and their ligneous vegetation with Myricaria germanica and riverine landscape diversity in the Eastern Alps: proposing the Isel river system for the Natura 2000 network Helmut Kudrnovsky

Motorcycling over the Ofenpass: Perception of the Swiss National Park and the Ofenpass from the perspective of motorcyclists Andrea Jauss \& Norman Backhaus

Crowding in Germany's national parks: the case of the low mountain range Saxon Switzerland National Park Johannes Schamel \& Hubert Job

Evaluation of hikers' pro-environmental behaviour in Triglav National Park, Slovenia Mojca Stubeli Ars

Case in point

Schwäbische Alb (Swabian Alb) Biosphere Reserve

Rüdiger Jooß

Management \& Policy Issues

Climate change and related management issues in the mountains of Southeastern Europe the Pirin National Park in Bulgaria Karsten Grunewald

Lessons learnt from a monitoring endeavour in the UNESCO Biosphere Reserve Entlebuch Florian Knaus

Valuing Alpine ecosystems: the recharge.green project will help decision-makers to reconcile renewable energy production and biodiversity conservation in the Alps

Karin Svadlenak-Gomez, Marianne Badura, Florian Kraxner, Sabine Fuss, Daniele Vettorato \& Chris Walzer

Sentinel lakes: a network for the study and management of mountain lakes in the French Alps and in Corsica Birck et al.

News

EuroMAB Meeting 2013, Frontenac Arch Biosphere Reserve, Brockville (Ontario, Canada), 15-19 October 2013

Published by:

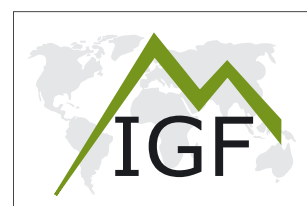

Interdisciplinary Mountain Research

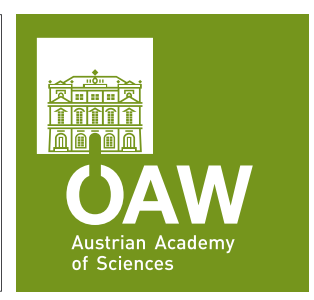

Publisher:

Austrian Academy of Sciences Press

Initiated by:
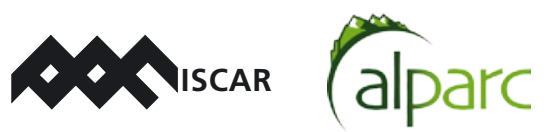

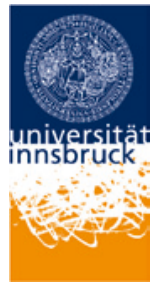

\section{innsbruck university press}

peer reviewed 